\title{
Sprache - Gedanken aus einem Sprechzimmer
}

Markus Gassner-Bachmann

Korrespondenz:

Dr. med.

Markus Gassner-Bachmann

Spitalstrasse 8

CH-9472 Grabs

m.gassner@hin.ch
Die Sprache ist ein wesentliches Merkmal des Menschen (Proprium). So lernten wir dies vor 50 Jahren in der Logik der scholastischen Philosophie, weil nur der Mensch denkt, spricht. Der Weg zur Universität war nur über gute Kenntnisse toter Sprachen (Griechisch, Latein) möglich. Englisch war nicht notwendig. Ein Bildungsluxus? Aber auch Tiere verständigen sich mit Lauten, teils recht musikalisch, wie manche Singvögel und Wale. Verbreitet in der Natur ist die nicht verbale Kommunikation. Auch der Mensch kann stumm sprechen - ein Blick genügt. Es gibt die Kunst, zwischen den Zeilen zu schreiben und zu lesen. Diese wird gepflegt, wenn man nicht sprechen darf. Die Sprache ist ein feines Werkzeug der Verständigung. Es gibt verschiedene Sprachen und grosse Unterschiede innerhalb der gleichen Sprache. Diese verrät die Herkunft. Früher gab es sogar markante Unterschiede innerhalb eines Wohnortes. Es gibt Linguisten, sie verstehen es, Sprachen, Wörter zu vergleichen.

Es ist unmöglich, alle Sprachen der Menschen zu lernen, aber jeder Mensch, der hören und sprechen kann, hat mindestens seine sogenannte Muttersprache. Es gibt andererseits keine Sprache, die wir nicht lernen könnten. Die Kunst, fremde Sprachen zu verstehen und zu sprechen, ist abhängig vom eigenen Wortschatz, der fremden Sprache, wie der eigenen. Wer nicht organisiert in fremde Länder reist, lernt sehr rasch die Bedeutung auch weniger Worte kennen. Nur ein Wort des Grusses und des Dankes bewirken bereits ausserordentlich viel.

Einige Beispiele über die Sprache aus der medizinischen Praxis: Bei einer Reise nach dem Staatsexamen in den Fernen Osten lernte ich ungefähr 50 chinesische Wörter. Als Assistent musste ich später einmal einen Chinesen auf der Durchreise mit akuten Bauchschmerzen behandeln. Er war sehr überrascht, dass ihn jemand in seiner Muttersprache etwas fragte. Seine Schmerzen waren dabei plötzlich vergessen. Er konnte seine Reise fortsetzen. Die Verwaltung fragte, was ich ihm denn gegeben hätte, er sei ja im Rollstuhl gebracht worden. Nichts, ich hatte nur mit ihm gesprochen.

Ein etwa 50-jähriger Mann kam mit seiner zweiten Frau wegen einer Bagatellerkrankung. Seine erste Frau war ein paar Jahre zuvor gestorben. Seine jetzige Frau sprach kein Wort Deutsch oder Englisch. Sie stammte aus einem Bergland im Fernen Osten. Ich fragte den Mann: «In welcher Sprache redet ihr denn miteinander?» Ein Achselzucken. «Woher kennen Sie denn Ihre Frau?» «Aus einem Katalog.» Glücklicherweise war die Frau nie ernstlich krank. Zwei Jahre später starb der
Mann, plötzlich, unerwartet. Erst jetzt ergaben sich Probleme mit der Frau. Sie hatte niemanden hier, war zwar plötzlich reich, aber unglücklich. Weil sie begann, ihr Vermögen zu verscherbeln, gab man ihr einen Vormund. Sie zog an einen andern Ort in der Schweiz. Mit wem spricht diese Schweizerin nun hier in unserem Land?

Eine Patientin aus dem Balkan ist hierher gezogen, zu ihrem Mann, der seit Jahrzehnten hier gearbeitet hat. Mit ihr kamen auch die Kinder. Sie spricht kein Wort Deutsch. Man findet einen Diabetes. Für die Diätberatung nimmt sie ihren 10-jährigen Sohn mit. Der Sohn besucht hier die Primarschule. Er hat auch hier Mühe mit seiner intellektuellen Teilleistungsschwäche. Die Diabeteseinstellung der Patientin ist ausserordentlich schwierig, man weiss nie, welche Tabletten sie tatsächlich genommen hat und weshalb sie manche nicht möchte. Eigentlich sollte man ihr Insulin geben, aber dann wird das Ganze noch viel unübersichtlicher, auch gefährlicher. Mehrmals hatte ich sie und ihren Mann über Deutschkurse informiert. Das mache ich bei all meinen Patienten, die nicht genügend Deutsch sprechen. Da ich den Effekt nicht quantitativ nachkontrolliere, kann ich die «Number needed to treat / learn» nicht berechnen. Vielleicht ist der Effekt etwa so gross wie beim Besprechen eines Nikotinabusus. Dieser liegt um ein Vielfaches höher als bei den meisten pharmakologischen Behandlungen.

Ich halte in meiner ärztlichen Praxis Sprechstunden. Es gibt auch ein paar Apparate. Sie sind weniger wichtig. Für die Diagnose ist die Anamnese wichtig, erst dann folgt der klinische Befund. Und für die Therapie wäre wieder die Sprache, die Anleitung etwas Wesentliches.

Vor 20 Jahren verabschiedete sich eine Patientin mit einer Carotisstenose links an der Theke. Plötzlich sagte sie nichts mehr und liess ihre Handtasche fallen, die sie mit der rechten Hand gehalten hatte. Minuten später sprach sie wieder und packte ihre Tasche. Sie wollte nicht wieder wegen der transitorischen Aphasie hospitalisiert werden und fuhr mit dem Postauto nach Hause. Ein paar Wochen später rief sie an, konnte sich aber nur noch mit «He, he» melden - genug, damit ich sie an der Stimme erkannte. Es war nicht das letzte Mal. Ich konnte sie gezielt fragen, ob ich sie sofort besuchen solle, und ob sie dieses oder jenes Medikament benötige. Je nachdem, wie sie ihr «He» sprach, wusste ich, ob sie ja oder nein meinte.

Herr Couchepin möchte, dass Patienten vor Konsultationen sich telephonisch beraten lassen müs$\operatorname{sen} \ldots$ 